\title{
Influenza A(H6N1) Virus in Dogs, Taiwan
}

\section{Hui-Ting Lin, ${ }^{1}$ Ching-Ho Wang, ${ }^{1}$ Ling-Ling Chueh, Bi-Ling Su, Lih-Chiann Wang}

We determined the prevalence of influenza A virus in dogs in Taiwan and isolated A/canine/Taiwan/E01/2014. Molecular analysis indicated that this isolate was closely related to influenza $A(H 6 N 1)$ viruses circulating in Taiwan and harbored the E627K substitution in the polymerase basic 2 protein, which indicated its ability to replicate in mammalian species.

Tnfections with influenza viruses are rare in dogs. HowLever, interspecies transmission of an equine influenza $\mathrm{A}(\mathrm{H} 3 \mathrm{~N} 8)$ virus to dogs was identified during a respiratory disease outbreak in Florida, USA, in 2004 (1). Influenza $\mathrm{A}(\mathrm{H} 6 \mathrm{~N} 1)$ virus is the most common naturally occurring avian influenza virus in Taiwan (2). Therefore, to determine to the prevalence of influenza A virus infection in dogs in Taiwan, we performed serologic analysis, 1-step reverse transcription PCR (RT-PCR) screening, and virus isolation.

\section{The Study}

A total 474 serum specimens were collected in Taiwan during October 2012-October 2013. Two hundred eighty-one specimens were collected from household (owned) dogs at the National Taiwan University Veterinary Hospital in Taipei. The remaining 193 serum specimens were obtained from free-roaming dogs in rural areas.

All serum specimens were tested for antibodies against influenza A virus by using a species-independent blocking ELISA (Influenza A Virus Antibody Test Kit; Idexx, Westbrook, ME, USA). All antibody-positive serum specimens were further tested by using a hemagglutination inhibition (HI) assay. HI was determined according to procedures recommended by the World Organisation for Animal Health. Chicken erythrocytes (1\%) were used. Serum samples were treated with receptor-destroying enzyme (Denka Seiken, Tokyo, Japan) before conducting the assay to destroy nonspecific inhibitors (3). A/chicken/Taiwan/2838V/2000 (H6N1) and A/chicken/Taiwan/1209/03 (H5N2) viruses were used as antigens.

Nasal swab specimens were collected from dogs with respiratory signs, such as nasal discharge, sneezing, coughing, at the National Taiwan University Veterinary Hospital during November 2012-February 2014. Specimens were suspended in viral transportation medium (Creative, Taipei, Taiwan), and RNA was extracted by using a commercial kit (Viral RNA Mini Kit; QIAGEN, Hilden, Germany)

Author affiliations: National Taiwan University, Taipei, Taiwan according to the manufacturer's instructions. A 1-step RTPCR was then performed by using the One-Step RT-PCR Kit (QIAGEN). A primer set (M52C/M253R) specific for a highly conserved region of matrix $(\mathrm{M})$ gene was used for detection of influenza A virus nucleotides (4). The remaining nasal swab suspension solutions from dogs positive by RT-PCR were used for virus isolation from 10-day-old specific pathogen-free chicken eggs (Animal Health Research Institute, Taipei, Taiwan).

Phylogenetic trees were constructed with complete nucleotide sequences obtained from the Global Initiative on Sharing All Influenza Data (http://platform.gisaid.org/epi3/ frontend\#185d95) and GenBank. Multiple sequence alignments and phylogenetic analyses were performed by using MEGA6 software (5). Sequences were aligned by using the ClustalW method (http://www.genome.jp/tools/clustalw/). Trees were constructed by using the maximum-likelihood method and analysis with 1,000 bootstrap replications.

A total of 3/281 (1.1\%) household dogs and 6/193 (3.1\%) free-roaming dogs were positive by ELISA for influenza A virus. The HI assay showed that 1 of the 9 viruspositive dogs had antibodies against influenza A(H6N1) virus (titer $=20$ ). This dog was from Yunlin, Taiwan, a rural area that is a major site for poultry production. No serum samples had antibodies against influenza A(H5N2) virus.

Nasal swab specimens from 4/185 (2.1\%) dogs were positive by RT-PCR for influenza virus M gene. All 4 RTPCR positive dogs had nasal discharges or coughing. Three of these dogs were $<6$ months of age and adopted from an animal shelter $(n=1)$ or rescued from the streets $(n=2)$. The fourth dog was a 15-year-old household pet.

Influenza A virus was isolated from a 4-month-old dog co-infected with canine distemper virus. The virus influenza isolate was designated A/canine/Taiwan/E01/2014 (GenBank accession nos. KM20333-KM203344). This dog was rescued from the streets and had severe purulent nasal discharge, cough, and fever. Chest radiographs showed a severe bilateral air bronchogram in the lung field. Serum specimens (collected on days 1, 7, 14, and 19 after hospitalization) from this dog were assessed by using ELISA and HI assay, but no seroconversion was observed.

Sequence homology of 8 influenza virus gene segments from A/canine/Taiwan/E01/2014 (H6N1) was compared with segments in the Global Initiative on Sharing All Influenza Data (Table 1). Hemagglutinin (HA) and neuraminidase (NA) genes of this virus had the highest nucleotide sequence similarity (99\%) with A/chicken/Taiwan/1843/2012 (H6N1) and A/chicken/Taiwan/2084/2012

${ }^{1}$ These authors contributed equally to this article. 
Table 1. Homology of nucleotide sequences of $A /$ canine/Taiwan/E01/2014 (H6N1) influenza virus isolated from dogs in Taiwan compared with related sequences from the Global Initiative on Sharing All Influenza Data* $\dagger$

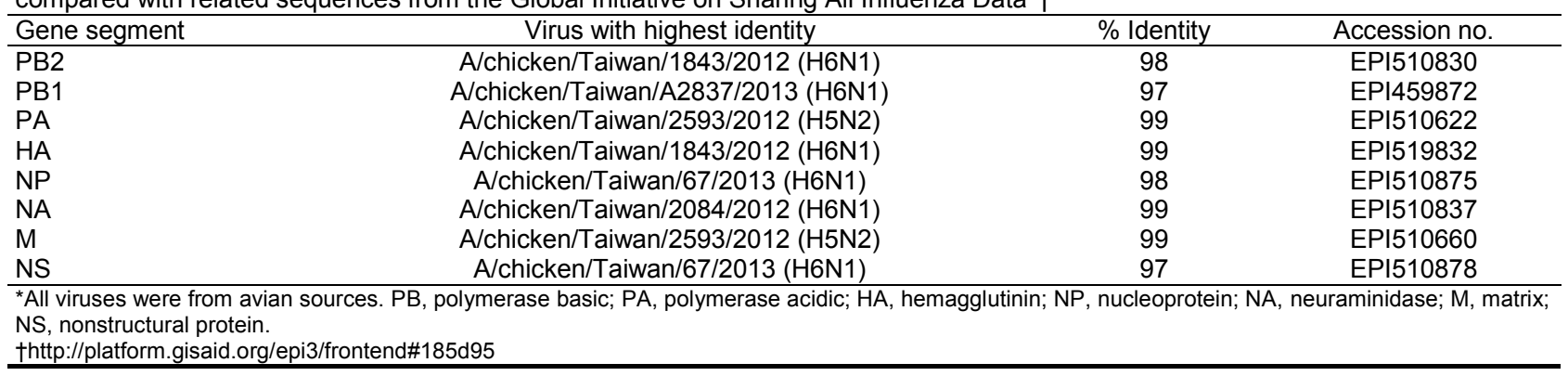

(H6N1), respectively. Polymerase basic 2 (PB2), PB1, nucleoprotein (NP), and nonstructural protein (NS) genes were closely related to those of H6N1 subtype virus isolates from chickens in Taiwan (similarity range $97 \%$ 99\%). Polymerase acidic (PA) and $\mathrm{M}$ genes had the highest nucleotide sequence similarity (99\%) to A/chicken/ Taiwan/2593/2012 (H5N2). On the basis of HA and NA sequence analysis results, A/canine/Taiwan/E01/2014 was designated an H6N1 subtype influenza virus.

Only 1 basic amino acid (PQIATR*G) was found at the HA cleavage site of A/canine/Taiwan/E01/2014. G228S substitution ( $\mathrm{H} 3$ numbering) on the receptor binding site for HA was also observed for this virus, which indicated increased virus binding ability for the $\alpha 2-6$ sialic acid receptor $(6,7)$. In NA, a 14-aa deletion in the NA stalk region was observed at aa positions $42-53$ and $68-69$, which is associated with virus circulation in domestic poultry. The amino acid $\mathrm{H} 275 \mathrm{Y}$ substitution (oseltamivir resistance marker) in NA was not found in this virus. In the M2 protein, A/canine/Taiwan/E01/2014 had an S31N substitution, which suggested resistance to admantanes $(8,9)$.

Other major signatures associated with replication ability in a mammalian host or pathogenicity were also observed, including E627K in the PB2 and the PDZ ligand domain at the $\mathrm{C}$-terminal region of NS1 of this virus. Additional molecular comparisons with H6N1 subtype virus (A/ Taiwan/2/2013) isolated from humans $(7,10,11)$ and from dogs experimentally infected H6N1 subtype virus (A/mallard/San-Jiang/275/2007) (12) were made (Table 2).

Phylogenetic analysis of HA and NA gene segments indicated that $\mathrm{A} /$ canine/Taiwan/E01/2014 belongs to the H6N1 lineage that has been circulating in chickens in Taiwan since 1997 (Figure, panels A, B). Although the lineage of internal gene segments (PB2, PB1, PA, NP, M, and NS) is composed mainly of H6N1 subtype viruses isolated in Taiwan, some H5N2 subtype isolates in the H6N1 lineage were observed

\begin{tabular}{|c|c|c|c|c|}
\hline \multirow{2}{*}{$\begin{array}{l}\text { Gene, amino acid } \\
\text { substitution }\end{array}$} & \multicolumn{3}{|c|}{ Virus } & \multirow[b]{2}{*}{ Function } \\
\hline & A/canine/Taiwan/E01/2014 & A/Taiwan/2/2013 & A/mallard/San-Jiang/275/2007 & \\
\hline \multicolumn{5}{|l|}{ PB2 } \\
\hline E627K & K & $E$ & $E$ & $\begin{array}{l}\text { Replication ability in } \\
\text { mammalian host }\end{array}$ \\
\hline D701Q & $\mathrm{D}$ & $\mathrm{D}$ & $\mathrm{D}$ & Nuclear import \\
\hline \multicolumn{5}{|l|}{ PB1-F2 } \\
\hline N66S & $\mathrm{N}$ & Truncated form & S & Induction of apoptosis \\
\hline \multicolumn{5}{|l|}{$\mathrm{HA}$} \\
\hline Cleavage site & $\begin{array}{c}\text { Single basic amino acid } \\
\text { (PQIATR+G) }\end{array}$ & $\begin{array}{l}\text { Single basic amino } \\
\text { acid (PQIATR+G) }\end{array}$ & $\begin{array}{c}\text { Single basic amino acid } \\
\text { (PQIETR+G) }\end{array}$ & HA cleavage \\
\hline Q226L & $Q$ & $Q$ & $Q$ & Increased virus binding \\
\hline G228S & S & $S$ & G & $\begin{array}{c}\text { ability of } \alpha 2-6 \text { sialic acid } \\
\text { receptor }\end{array}$ \\
\hline \multicolumn{5}{|r|}{$e^{\prime}$} \\
\hline $\begin{array}{l}\mathrm{H} 275 \mathrm{Y} \\
41-52 \text { and } 68-69 \\
\text { deletions }\end{array}$ & $\begin{array}{c}\mathrm{H} \\
\text { Deleted }\end{array}$ & $\begin{array}{c}\mathrm{H} \\
\text { Deleted }\end{array}$ & $\begin{array}{c}\mathrm{H} \\
\text { Complete }\end{array}$ & $\begin{array}{l}\text { Oseltamivir resistance } \\
\text { Adaptation hallmark of } \\
\text { waterfowl viruses to } \\
\text { terrestrial poultry }\end{array}$ \\
\hline \multicolumn{5}{|r|}{ 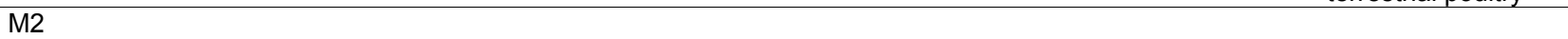 } \\
\hline S31N & $\mathrm{N}$ & $\mathrm{N}$ & S & Adamantane resistance \\
\hline \multicolumn{5}{|l|}{ NS1 } \\
\hline $\begin{array}{l}\text { D92E } \\
\text { EPEV sequence } \\
\text { (C-terminus) }\end{array}$ & $\begin{array}{c}\text { D } \\
\text { EPEV }\end{array}$ & $\begin{array}{c}\text { D } \\
\text { EPEV }\end{array}$ & $\begin{array}{c}\text { D } \\
\text { ESEV }\end{array}$ & $\begin{array}{l}\text { Unknown } \\
\text { PDZ ligand domain }\end{array}$ \\
\hline
\end{tabular}

*PB, polymerase basic; HA, hemagglutinin; NA, neuraminidase; M, matrix; NS, nonstructural protein. †HA cleavage site. 


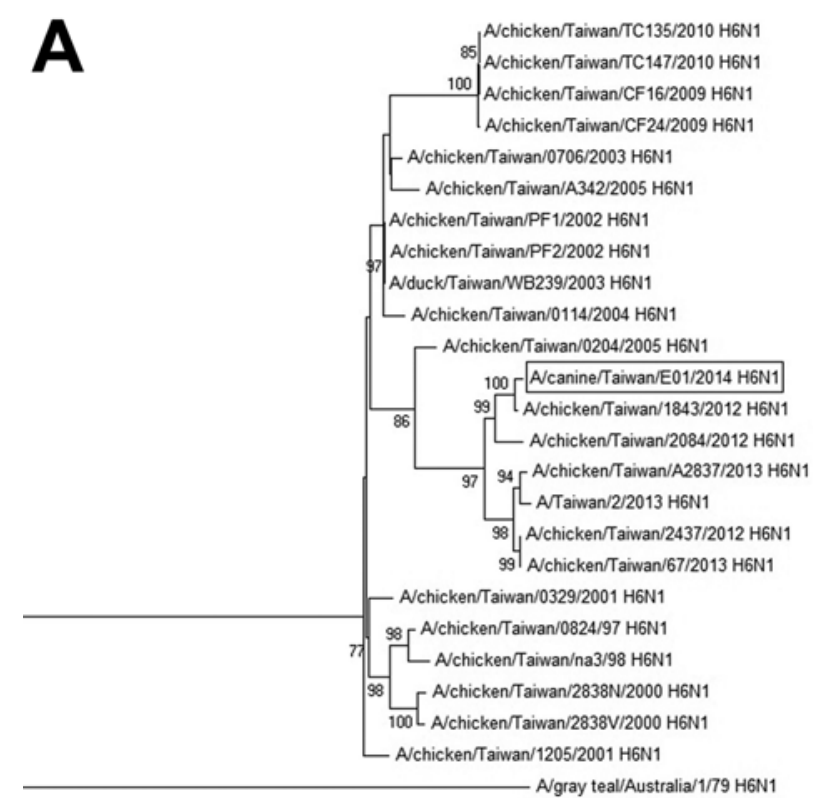

A/gray teal/Australia/1/79 H6N1

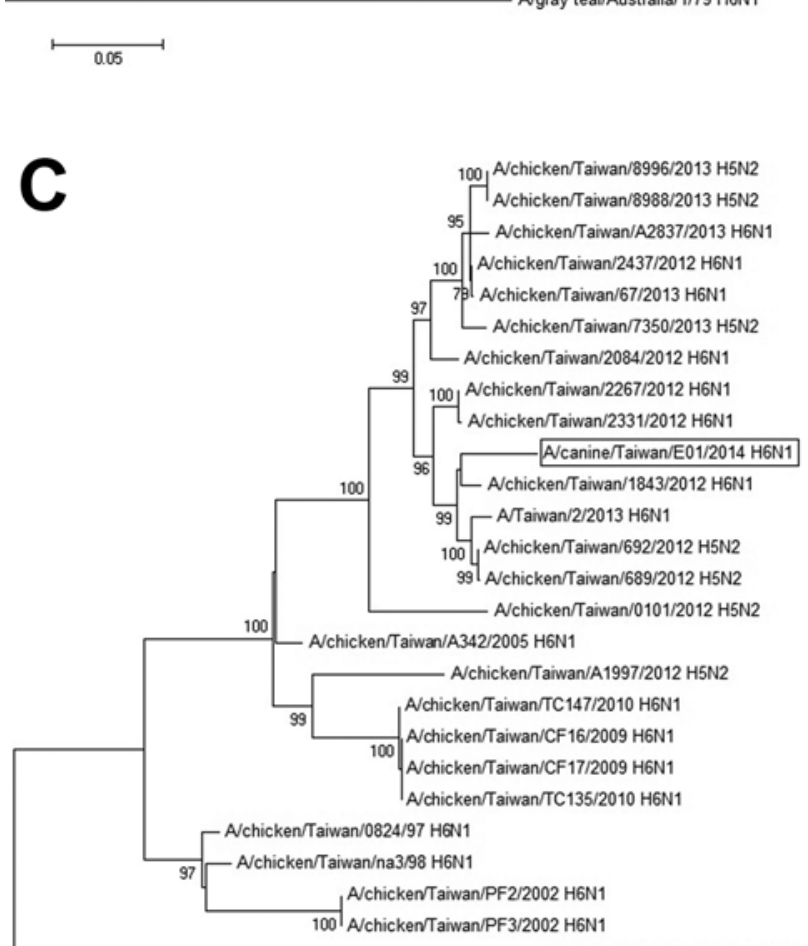

A/gray teal/Australia/1/79 H6N1

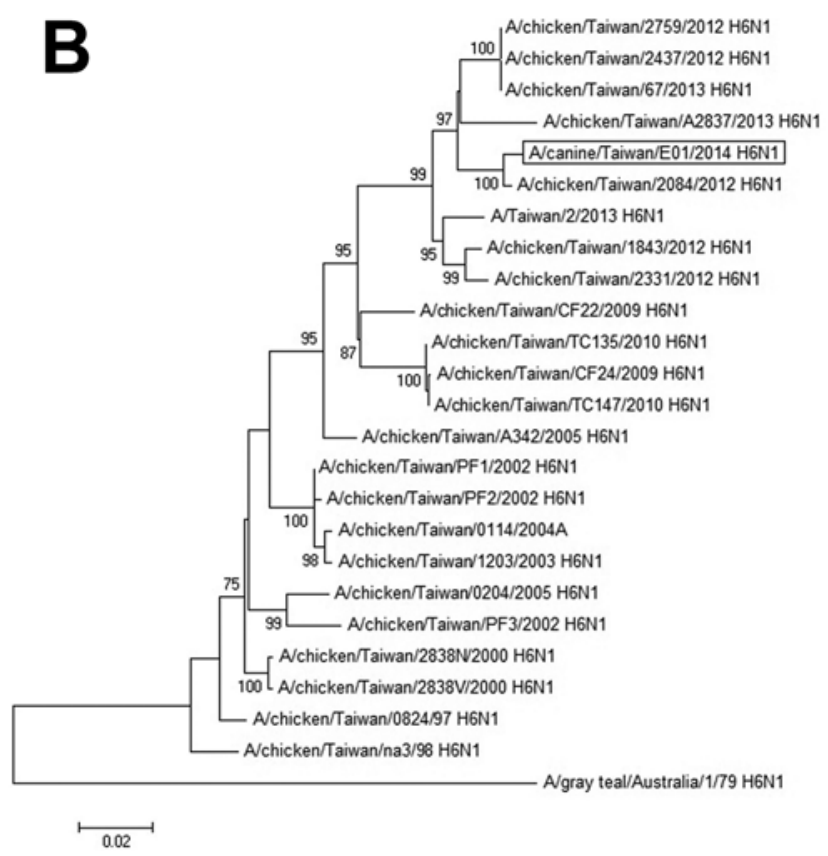

Figure. Phylogenetic relationship between influenza $A(\mathrm{H} 6 \mathrm{~N} 1)$ virus $\mathrm{A} /$ canine/Taiwan/E01/2014 isolated from dogs in Taiwan (boxes) and other influenza A virus lineages. Maximumlikelihood analysis with bootstrap analysis was conducted with 1,000 replications. Only branches with bootstrap values $>75 \%$ are indicated on phylogenetic trees. A) Hemagglutinin, B) neuraminidase, and $C$ ) polymerase basic 2 genes of $A /$ canine/ Taiwan/E01/2014 are clustered with H6N1 subtype strains isolated in Taiwan during 2012-2013 in Taiwan. Scale bars indicate nucleotide substitutions per site.
(Figure, panel C; online Technical Appendix, http://wwwnc. cdc.gov/EID/article/21/12/14-1229-Techapp1.pdf).

\section{Conclusions}

Avian influenza A(H6N1) viruses have been widespread in chickens in Taiwan since 1972 (13-15). These viruses are clustered in a unique lineage that differs from viruses circulating in Hong Kong and southeastern China since 1997
(13). Unlike avian species, H6 subtype virus infections are rare in mammals.

In this study, 9 of 474 dog serum specimens were positive for influenza A virus by ELISA, and 4/185 (2.1\%) dogs had RT-PCR-positive results for this virus. $\mathrm{A} /$ canine/Taiwan/E01/2014 was isolated from 1 dog that was co-infected with canine distemper virus. On the basis of molecular analysis of A/canine/Taiwan/E01/2014, HA, 
NA, PB1, PB2, NP, and NS genes showed high homology ( $>97 \%$ nucleotide identity) with avian H6N1 subtype virus isolates that are currently prevalent in Taiwan. $\mathrm{PA}$ and $\mathrm{M}$ genes of $\mathrm{A} /$ canine/Taiwan/E01/2014 showed $99 \%$ nucleotide identity with A/chicken/Taiwan/2593/ 2013 (H5N2).

Phylogenetic analysis showed that 8 eight virus genes were derived from H6N1 subtype viruses isolated in Taiwan. All 8 influenza virus genes found in the dog probably originated from avian sources. We speculate that a complete avian influenza virus had infected this dog. However, additional analysis is required to verify this hypothesis.

\section{Acknowledgments}

We thank the staff of the Heart of Taiwan Animal Care and $\mathrm{Na}-$ tional Taiwan University Veterinary Hospital for their assistance in sample collection.

Dr Lin is a postgraduate scientist at the National Taiwan University Veterinary Hospital, Taipei, Taiwan. Her research interests are veterinary virology and internal medicine in companion animals.

\section{References}

1. Crawford PC, Dubovi EJ, Castleman WL, Stephenson I, Gibbs EPJ, Chen L, et al. Transmission of equine influenza virus to dogs. Science. 2005;310:482-5. http://dx.doi.org/10.1126/ science. 1117950

2. Chen YT, Juang RH, He JL, Chu WY, Wang CH. Detection of H6 influenza antibody by blocking enzyme-linked immunosorbent assay. Vet Microbiol. 2010;142:205-10. http://dx.doi.org/10.1016/ j.vetmic.2009.09.064

3. Jirjis FF, Deshpande MS, Tubbs AL, Jayappa H, Lakshmanan N, Wasmoen TL. Transmission of canine influenza virus (H3N8) among susceptible dogs. Vet Microbiol. 2010;144:303-9. http://dx.doi.org/10.1016/j.vetmic.2010.02.029

4. Fouchier RA, Bestebroer TM, Herfst S, Van Der Kemp L, Rimmelzwaan GF, Osterhaus AD. Detection of influenza A viruses from different species by PCR amplification of conserved sequences in the matrix gene. J Clin Microbiol. 2000;38:4096-101.

5. Tamura K, Stecher G, Peterson D, Filipski A, Kumar S. MEGA6: molecular evolutionary genetics analysis version 6.0. Mol Biol Evol. 2013;30:2725-9. http://dx.doi.org/10.1093/molbev/mst197

6. Stevens J, Blixt O, Tumpey TM, Taubenberger JK, Paulson JC, Wilson IA. Structure and receptor specificity of the hemagglutinin from an H5N1 influenza virus. Science. 2006;312:404-10. http://dx.doi.org/10.1126/science.1124513

7. Wei SH, Yang JR, Wu HS, Chang MC, Lin JS, Lin CY, et al. Human infection with avian influenza A H6N1 virus: an epidemiological analysis. Lancet Respir Med. 2013;1:771-8.

8. Pinto LH, Holsinger LJ, Lamb RA. Influenza virus M2 protein has ion channel activity. Cell. 1992;69:517-28. http://dx.doi.org/ 10.1016/0092-8674(92)90452-I

9. Holsinger LJ, Nichani D, Pinto LH, Lamb RA. Influenza A virus M2 ion channel protein: a structure-function analysis. J Virol. 1994;68:1551-63.

10. Shi W, Shi Y, Wu Y, Liu D, Gao GF. Origin and molecular characterization of the human-infecting H6N1 influenza virus in Taiwan. Protein Cell. 2013;4:846-53. http://dx.doi.org/10.1007/ s13238-013-3083-0

11. Yuan J, Zhang L, Kan X, Jiang L, Yang J, Guo Z, et al. Origin and molecular characteristics of a novel 2013 avian influenza A (H6N1) virus causing human infection in Taiwan. Clin Infect Dis. 2013;57:1367-8. http://dx.doi.org/10.1093/cid/cit479

12. Cheng K, Yu Z, Gao Y, Xia X, He H, Hua Y, et al. Experimental infection of dogs with $\mathrm{H} 6 \mathrm{~N} 1$ avian influenza A virus. Arch Virol. 2014;159:2275-82. http://dx.doi.org/10.1007/s00705-014-2058-7

13. Lee MS, Chang PC, Shien JH, Cheng MC, Chen CL, Shieh HK. Genetic and pathogenic characterization of H6N1 avian influenza viruses isolated in Taiwan between 1972 and 2005. Avian Dis. 2006;50:561-71. http://dx.doi.org/10.1637/7640-050106R.1

14. Lu YS, Sugimura T, Shieh HK, Lee YL, Jong MH. Isolation and identification of an influenza A virus in ducks in Taiwan. Journal of the Chinese Society of Veterinary Medicine. 1985;11:23-34.

15. Lee HC, Hsu CN, Kuo TF, Wang CH. Molecular epidemiology of avian influenza virus H6N1 in Taiwan from 2000 to 2003. Taiwan Veterinary Journal. 2005;31:230-9.

Address for correspondence: Lih-Chiann Wang, Institute of Veterinary Clinical Sciences, National Taiwan University. No 1, Sec 4, Roosevelt Rd, Taipei 10617, Taiwan; email: lcwang@ntu.edu.tw

\section{Bat Flight and Zoonotic Viruses}
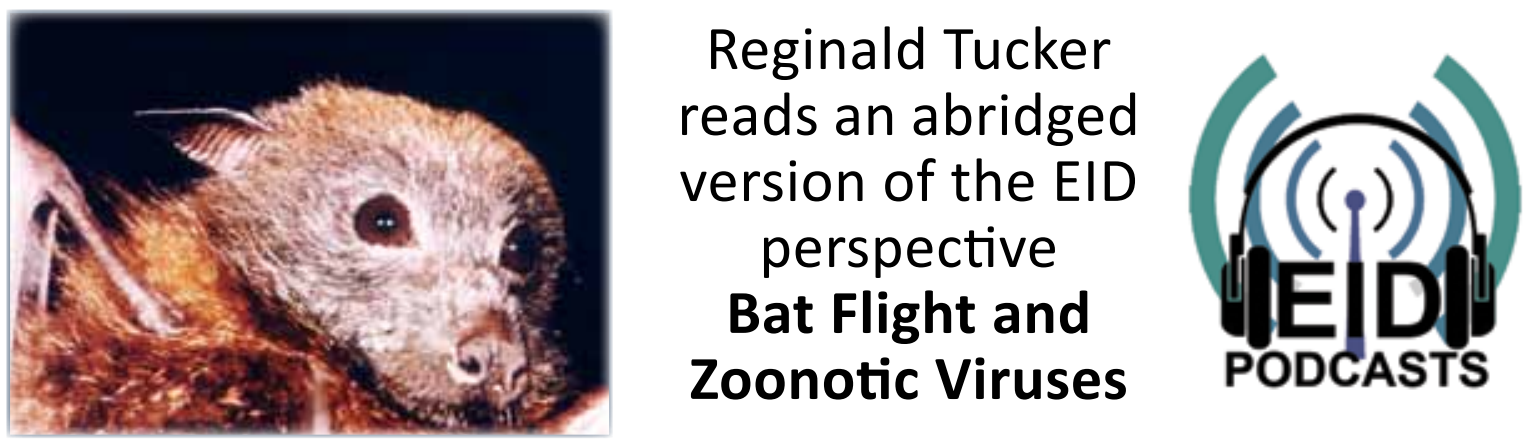

http://www2c.cdc.gov/podcasts/player.asp?f $=8632573$ 